\title{
FIRST EURADOS INTERCOMPARISON EXERCISE OF EYE LENS DOSEMETERS FOR MEDICAL APPLICATIONS
}

\author{
I. Clairand $^{1, *}$, M. Ginjaume ${ }^{2}$, F. Vanhavere ${ }^{3}$, E. Carinou ${ }^{4}$, J. Daures $^{5}$, M. Denoziere ${ }^{5}$, E. Honorio da Silva ${ }^{3}$, \\ M. Roig ${ }^{2}$, S. Principi ${ }^{2}$, L. Van Rycheghem ${ }^{1}$. \\ ${ }^{1}$ Institute for Radiological Protection and Nuclear Safety (IRSN), B.P. 17, 92262 Fontenay-aux-Roses, France \\ ${ }^{2}$ Universitat Politcnica de Catalunya (UPC), Diagonal 647, E-08028 Barcelona, Spain. \\ ${ }^{3}$ Belgian Nuclear Research Centre (SCK-CEN), Boeretang 200, BE-2400 Mol, Belgium. \\ ${ }^{4}$ Greek Atomic Energy Commission (GAEC), P.O. Box 60092, Agia Paraskevi, 15310 Athens, Greece. \\ ${ }^{5}$ CEA-LIST Laboratoire National Henri Becquerel (CEA-LNHB), CEA Saclay, 91191 Gif-sur-Yvette, France.
}

\section{Received month date year, amended month date year, accepted month date year}

In the context of the decrease of the eye lens dose limit for occupational exposure to $20 \mathrm{mSv}$ per year stated by the recent revision of the European Basic Safety Standards Directive 2013/59/EURATOM, the European Radiation Dosimetry Group (EURADOS) has organized in 2014, for the first time, an intercomparison exercise for eye lens dosemeters. The main objective was to assess the capabilities of the passive eye lens dosemeters currently in use in Europe for occupational monitoring in medical fields. A total of 20 European individual monitoring services from 15 different countries have participated. The dosemeters provided by the participants were all composed of thermoluminescent detectors, of various types and designs. The irradiations were carried out with several photon fields chosen to cover the energy and angle ranges encountered in medical workplaces. Participants were asked to report the doses in terms of $H_{\mathrm{p}}(3)$ using their routine protocol. The results provided by each participant were compared to the reference delivered doses. All the results were anonymously analyzed. Results are globally satisfactory since, among the 20 participants, 17 were able to provide $90 \%$ of their response in accordance to the ISO 14146 standard requirements.

For many years, the European Radiation Dosimetry Group (EURADOS) has been organizing intercomparison (IC) exercises $^{(1)}$ dedicated to Individual Monitoring Services (IMS). These exercises give IMS the opportunity to compare results with other participants and develop plans for improving their dosimetry systems. Up to now, EURADOS organized three IC for whole-body photon dosemeters (IC2008, IC2010, IC2012 $\left.{ }^{(2)}\right)$, one for whole-body neutron dosemeters (IC2012 $)^{(3)}$, one for extremity dosemeters for photon and beta fields (IC2009 $9_{\text {ext }}$ ) and, very recently, one for environmental dosemeters (IC2014 ${ }_{\text {env }}$ ).

In the context of the decrease of the eye lens dose limit for occupational exposure to $20 \mathrm{mSv}$ per year stated by the recent revision of the European Basic Safety Standards Directive 2013/59/EURATOM ${ }^{(4)}$, EURADOS organized in 2014, for the first time, an IC exercise specifically dedicated for eye lens dosemeters in the medical field, so called IC2014 $4_{\text {eye }}$.

\section{MATERIAL AND METHODS}

\section{Scope and organization of IC2014}

IC2014 eye was organized to assess the capabilities of the passive eye lens dosemeters currently in use in
Europe for occupational monitoring in the medical field to measure the personal dose equivalent $H_{\mathrm{p}}(3)$. The eye lens dosemeters were irradiated with Cs-137 sources as a reference, and with other photon fields chosen to cover the energy and angle ranges encountered at medical workplaces.

An Organization Group (OG) composed of members of EURADOS Working Group 12 was appointed to organize and realize this IC. All participants were requested to prepare their dosemeters according to their normal procedures and to label them with codes provided by the OG coordinator in charge of the reception and dispatching of the dosemeters to the irradiation laboratories. Participants were asked to report the doses in terms of $H_{\mathrm{p}}(3)$ using their routine protocol.

All the data processed by the OG members were treated confidentially using an identification code composed of three letters (XXX) assigned to each participant. This IC was designed to be a blind test for all participants who had to report their results without knowing the details of the irradiation plan nor the reference dose values. The only information they had was that the irradiations were performed with several photon fields similar to the ones encountered at

\footnotetext{
*Corresponding author: isabelle.clairand@irsn.fr
} 
medical workplaces.

\section{Participants}

A total of 20 European IMS from 15 different countries participated (Austria, Belgium, Czech Republic, France, Greece, Italy, Lithuania, Poland, Rumania, Serbia, Slovakia, Spain, Switzerland, UK and Ukraine). Participation was on a voluntary basis, given a participation fee.

The dosemeters provided by the participants were all composed of thermoluminescent detectors. Among the 20 participants, 9 provided the Eye- $\mathrm{D}^{\mathrm{TM}}$ system developed during the ORAMED European project ${ }^{(5)}$ and the other participants provided different systems of various designs as presented in Figure 1. In addition, each participant was kindly requested to fill in a questionnaire indicating, in particular, the type of detector and the calibration method.

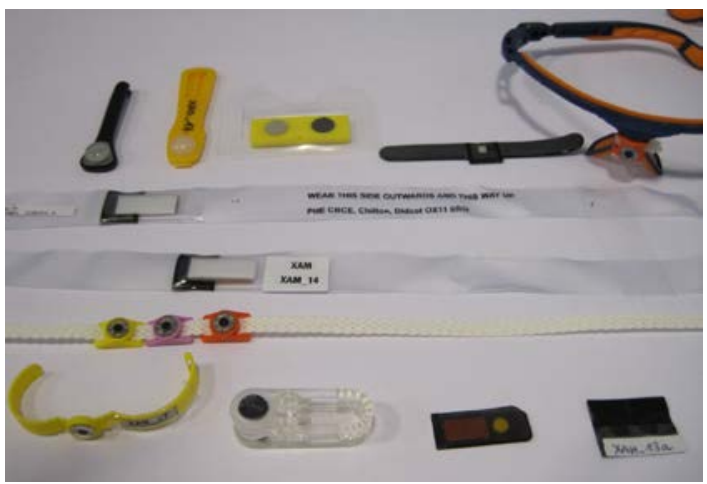

Figure 1. Photo of the different types of dosemeters provided by the participants for the IC2014

\section{Methodology followed for irradiations}

In total, 10 irradiation configurations were chosen for this IC. Three Cs setups were chosen to be used as a reference for the response of the dosemeters. The rest of the setups were chosen to be representative, in terms of mean energy and angle of incidence, of the photon fields encountered at medical workplaces. These photon fields were taken from ISO 4037 - part $1^{(6)}$ and IEC $61267^{(7)}$ standards. A specific configuration, so called "realistic field", representative of the scattered field encountered in interventional radiology at the level of the operator was used ${ }^{(8)}$. Table 1 shows a summary of the actual doses imparted for each radiation beam quality.

The irradiations were performed according to ISO 4037 - part 3 standard $^{(9)}$.The phantom that was used is the the cylindrical head phantom $(20 \mathrm{~cm} * 20 \mathrm{~cm})^{(10)}$ developed during the ORAMED European project ${ }^{(5)}$. Conversion coefficients to relate air kerma to $H_{\mathrm{p}}(3)$ were taken from Behrens et al. ${ }^{(11)}$ for beam qualities from ISO 4037 standard $^{(6)}$. To be completed...

Two dosemeters of each participant were irradiated for each setup.

The irradiations were carried out at SCK-CEN (Belgium), UPC (Spain), CEA (France) and IRSN (France) calibration laboratories.

\section{Background and transit dose control}

In total, each participant provided 38 dosemeters. Twenty dosemeters were used for the irradiations Twelve dosemeters were reserved for transit dose correction (3 dosemeters were dispatched to each of the 4 irradiation laboratories)., The transit dose was taken into account by the OG. The background was subtracted by each participant according to the IMS routine procedure. Six dosemeters were reserved to be used by the irradiation laboratories in case of damage or false irradiation. In the end, only a very few dosemeters were used for this purpose.

Table 1. Irradiation plan of the intercomparison: radiation qualities and angles of incidence, mean energy (keV) and range of imparted doses in terms of personal dose equivalent $H_{\mathrm{p}}(3)$ in $\mathrm{mSv}$.

\begin{tabular}{ccc}
\hline $\begin{array}{c}\text { Radiation quality } \\
\text { and angle of } \\
\text { incidence }\end{array}$ & $\begin{array}{c}\text { Mean energy } \\
(\mathrm{keV})\end{array}$ & $\begin{array}{c}\text { Dose range } \\
\left(H_{\mathrm{p}}(3), \mathrm{mSv}\right)\end{array}$ \\
\hline S-Cs; 0 & 667 & $0.4-0.5$ \\
S-Cs; 0 & 667 & $2.0-2.2$ \\
S-Cs; 60 & 667 & $2.0-2.1$ \\
N-40; 0 & 33 & $3.0-3.1$ \\
N-60; $00^{\circ}$ & 48 & $3.0-3.1$ \\
N-80; $0^{\circ}$ & 75 & $3.0-3.1$ \\
RQR6; $0^{\circ}$ & 44 & $2.6-2.7$ \\
RQR6; 45 & 44 & $2.5-2.6$ \\
RQR6; 75 & 44 & $2.1-2.2$ \\
Realistic field & 45 & $0.9-1.0$ \\
\hline
\end{tabular}

${ }^{1}$ Specific configuration representative of the scattered field encountered in interventional radiology at the level of the operator $^{(8)}$.

\section{Criteria for the evaluation of the results}

The numerical results in this intercomparison are reported as the dosemeter response $\mathrm{R}$, where $\mathrm{R}$ is defined as the value of the dose measured by the 
participant and corrected for background and transit dose, $H_{\mathrm{p}}(3)$, divided by the reference value, $H_{\mathrm{p}}(3)_{\mathrm{c}}$, given by the irradiation laboratory. For the analysis of the global results, the performance limits according to ISO 14146 standard $^{(13)}$, commonly known as «trumpet curves» were adopted:

$$
\frac{1}{F}\left(1-\frac{2 H_{0}}{H_{0}+H_{c}}\right) \leq R \leq F\left(1+\frac{2 H_{0}}{H_{0}+H_{c}}\right)(1)
$$

where $H_{\mathrm{C}}$ is the conventional true value, , $\mathrm{R}$ is the response, , $\mathrm{F}=1.5$ following the recommendations of ICRP 75 report $^{(15)}$ and $H_{0}$ is the "lower limit of the dose range for which the system has been approved" as it is mentioned in the ISO 14146 standard $^{(13)}$. For this IC, $H_{0}$ was not asked to each participant. Instead, a value of $0.085 \mathrm{mSv}$ was chosen for all participants, assuming a "lower limit of the dose range" of $1 \mathrm{mSv}$ in a year, and an issuing frequency of 12 per year. This value has already been chosen in the case of a previous EURADOS IC for whole body dosemeters ${ }^{(2)}$.

\section{RESULTS AND DISCUSSION}

\section{Individual result datasheets}

First individual draft results were sent to each participant in February 2015. Participants were asked to confirm the results or if they considered that corrections should be made because of errors made by the OG, to indicate what should be corrected and why. The OG decided on the corrections on an individual basis. Final results and certificate of attendance were sent to each participant in May 2015.

\section{Description and analysis of the results}

Figure 2 gives a general overview of the response values $\mathrm{R}$ as a function of the reference doses $H_{\mathrm{C}}$ $\left(H_{\mathrm{p}}(3)_{\text {reference}}\right)$ and shows that $93 \%$ of the results are within the trumpet curves built according to equation (1). This percentage differs based on the various setups. It is $100 \%$ for $\mathrm{S}-\mathrm{Cs}$ and $\mathrm{N}-80$ setups, since these qualities were chosen for the calibration by most of the participants. This value decreases slightly for lower energy configurations: it is equal to $95 \%$ for the realistic field and to $86 \%$ for N-40, N-60 and RQR6 setups. The lowest value is $77 \%$ for the "RQR6; $75^{\circ}$ " setup which corresponds to low energy and large angle irradiation setup.

Figure 3 gives the distribution of the response values for each irradiation setup using a box plot representation showing the minimum, $1^{\text {st }}$ quartile, median, $3^{\text {rd }}$ quartile and maximum responses. It can be noticed that the median of responses is very close to 1 for S-Cs beam quality setups, whereas the median of the responses ranges from 0.95 to 1.16 for $\mathrm{N}$ series and from 1.13 to 1.23 for RQR series. The median of responses is equal to 1.1 for the realistic field.

Among the 20 participants, for 14 of the them the response is $100 \%$ within the limits set by the ISO 14146 standard $^{(13)}$ for all setups, while for 17 the response is $90 \%$. '. Regarding the outliers, 1 participant is out of the limits for low energy setups, 3 are out of the limits for large angle setups and 2 are out of the limits for both of these types of setup. Figure 4 presents the distribution of results, using box plots, for each participant in an anonymous manner. A relatively large variability is observed among participants, the median of responses ranges from 0.72 to 1.67 .

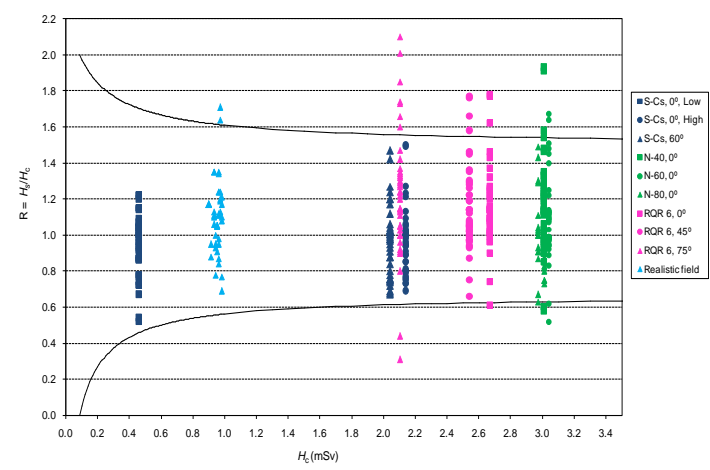

Figure 2. Summary of all reported response values $\mathrm{R}$ as a function of reference doses $H_{\mathrm{c}}$. The trumpet curves are built according to equation (1).

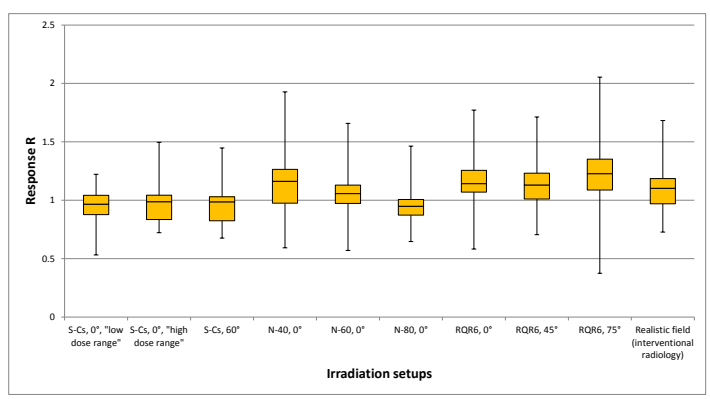

Figure 3. Box plot showing the minimum, $1^{\text {st }}$ quartile, median, $3^{\text {rd }}$ quartile and maximum responses, $R$, per irradiation setup. 


\section{CLAIRAND}

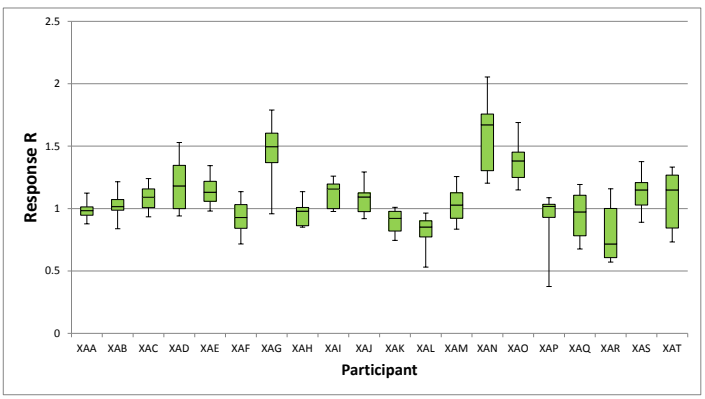

Figure 4. Box plot showing the minimum, $1^{\text {st }}$ quartile, median, $3^{\text {rd }}$ quartile, maximum responses $\mathrm{R}$ for each participant.

Using the questionnaires filled by the participants, the information regarding the calibration method is of interest to help in the interpretation of the results. In particular, regarding the calibration beam quality, 9 participants use pure S-Cs, 3 participants use mixed $\mathrm{S}$-Cs and X-ray and 8 use various $\mathrm{X}$-ray spectra. It appears that all the outliers for setups characterized by low energies use pure S-Cs to perform their calibration. Still, a majority of participants using pure S-Cs has correct results. The outliers for large angle setups can mainly be explained by the shape of the dosemeters. This type of analysis cannot be conducted deeper in such a study to respect the anonymity of results.

\section{CONCLUSION}

EURADOS organized, for the first time, an IC exercise specifically dedicated for eye lens dosemeters in the medical field. This IC gives an overview of the different dosimetric systems currently available in Europe for eye lens dose monitoring. This is particularly of interest in the context of the decrease of the eye lens dose limit for occupational exposure to $20 \mathrm{mSv}$ per year.

Results are globally satisfactory since, among the 20 participants, 17 are able to provide $90 \%$ of their response in accordance to the ISO 14146 standard $^{(13)}$ requirements. For a minority of participants some discrepancies compared to reference doses were observed for the irradiations setups characterized by large angles and/or low energies. Some participants could improve the performance of their system by improving their calibration methodology.

This type of IC on eye lens dosemeters should be performed regularly through the self-sustained programme of regular IC of EURADOS.

\section{ACKNOWLEDGEMENTS}

The authors would like to acknowledge all the participant laboratories both for taking part in this IC exercise and also for providing information on their routine dosimetry procedures. The authors wish to thank their colleagues from EURADOS for their help in the organization and for the many useful discussions.

\section{REFERENCES}

1. Grimbergen, T. W. M., Figel, M., Romero, A. M., Stadtmann, H., McWhan, A. F., EURADOS selfsustained programme of intercomparisons for individual monitoring services. Radiat. Prot. Dosim. 144(1-4), 266274 (2011).

2. Grimbergen, T. W. M., Figel, M., Romero, A. M., Stadtmann, H. and McWhan, A. F. EURADOS Intercomparison 2008 for Whole Body Dosemeters in Photon Fields. EURADOS Report 2012-01 ISSN 22268057 ISBN 978-3-943701-00-5 Braunschweig (2012).

3. Fantuzzi, E., Chevallier, M.-A., Cruz-Suarez R., LuszikBhadra M., Mayer S., Thomas D. J., Tanner R. and Vanhavere F. EURADOS IC2012n: EURADOS 2012 intercomparison for whole-body neutron dosimetry. Radiat. Prot. Dosim. 161(1-4), 73-77(2014).

4. Council Directive 2013/59/Euratom of 5 December 2013 laying down basic safety standards for protection against the dangers arising from exposure to ionising radiation, and repealing Directives 89/618/Euratom, 90/641/Euratom, 96/29/Euratom, 97/43/Euratom and 2003/122/Euratom. Official Journal L-13 of 17 January 2014.

5. Vanhavere, F., Carinou, E., Gualdrini, G., Clairand, I., Sans Merce, M., Ginjaume, M., Nikodemova, D., Jankowski, J., Bordy, J-M., Rimpler, A., Wach, S., Martin, P., Struelens, L., Krim, S., Koukorava, C., Ferrari, P., Mariotti, F., Fantuzzi, E., Donadille, L., Itié, C., Ruiz, N., Carnicer, A., Fulop, M., Domienik, J., Brodecki, M., Daures, J., Barth, I., Bilski, P. ORAMED: Optimization of Radiation Protection of Medical Staff. EURADOS Report 2012-02, ISSN 2226-8057, ISBN 978-3-94370101-2. Braunschweig (2012)

6. International organization for standardization. $\mathrm{X}$ and gamma reference radiation for calibrating dosemeters and doserate meters and for determining their response as a function of photon energy - part 1 radiation characteristics and production methods. ISO 4037 (Geneva: ISO) (1999).

7. International electro technical commission (IEC) Medical diagnostic X-ray equipment-radiation conditions for use in the determination of characteristics. $61267 \mathrm{Ed}$. 2.0. IEC (2005).

8. Bordy, J-M., Daures, J., Clairand, I., Denozière, M., Gouriou, J., Itié, C., Struelens, L., Donadille, L., and Schultz. Proceedings of the International Workshop on Uncertainty Assessment in Computational Dosimetry, a comparison of approaches. Design of a realistic calibration field for diagnostic radiology (medical staff dosimetry) ISBN 978-3-9805741-9-8 (Bologna, ENEA) (2007).

9. International organization for standardization. $\mathrm{X}$ and gamma reference radiation for calibrating dosemeters and doserate meters and for determining their response as a function of photon energy -- part 3: calibration of area and personal dosemeters and the measurement of their 
response as a function of energy and angle of incidence. ISO 4037 (Geneva: ISO) (1996).

10. Gualdrini, G., Mariotti, F., Wach, S., Bilski, P., Denoziere, M., Daures, J., Bordy, J.-M., Ferrari, P., Monteventi, F., Fantuzzi, E., Vanhavere F. A new cylindrical phantom for eye lens dosimetry development. Radiation Measurements 46(11), 1231-1234 (2011)

11. Behrens, R. and Dietze, G., 2011 Dose conversion coefficients for photon exposure of the human eye lens Phys. Med. Biol. 56, 415-437 (2011).

12. International organization for standardization and international electro technical commission. General requirements for the competence of testing and calibration laboratories. 17025 (Geneva: ISO) (1999).

13. International organization for standardization. Radiation protection - criteria and performance limits for the periodic evaluation of processors of personal dosemeters for $\mathrm{X}$ and gamma radiation. ISO 14146 (Geneva: ISO) (2000).

14. International commission on radiological protection. General principles for the radiation protection of workers. ICRP publication 75. Ann. ICRP 27(1). Pergamon (1997).

15. Principi S., Guardiola C., Duch M.A., Ginjaume M.. Air kerma to $\mathrm{Hp}(3)$ conversion coefficients for IEC 61267 RQR X-ray radiation qualities. Application to dose monitoring of the lens of the eye in medical diagnostics. International Conference on Individual Monitoring of Ionizing Radiation, Bruges 2015. 